\title{
PROLONGED ORGANIC PSYCHOSIS WITH RECOVERY IN ADDISON'S DISEASE
}

\author{
BY \\ SAMUEL I. COHEN and I. M. MARKS \\ From the Maudsley Hospital, Denmark Hill, London
}

This case of Addison's disease is unusual in that recovery from hypoglycaemic coma was followed by an organic psychosis lasting two months from which the patient completely recovered with treatment.

\section{Case Report}

A 38-year-old housewife was admitted to the London Hospital in coma on August 7, 1960. In 1950 her only child was born, following a mild toxaemia of pregnancy and a prolonged labour. She lactated for eight months. Her periods began again normally but about a year later they became infrequent, and finally ceased in 1953. For four years she had noticed that her skin had been getting darker, and she had had unexplained episodes of headache and vomiting each lasting about a day. These episodes had become more frequent in the four months preceding admission, and during this time she had lost some weight. On the morning of admission her husband had been unable to wake her.

Course in London Hospital.--She was a slightly-built woman, in deep coma, with a generalized deep-brown pigmentation of the skin. There were patches of pigment on the lips and on the buccal mucosa. Axillary and pubic hair were absent. She had marked dental caries. The pulse rate was 100 per minute and the blood pressure $95 / 60 \mathrm{~mm}$. Hg. The pupils were widely dilated and reacted to light. The limbs showed extensor rigidity with increased tendon reflexes, and the plantar responses were extensor. The blood sugar was $20 \mathrm{mg}$. per $100 \mathrm{ml}$; the plasma contained $140 \mathrm{mEq}$. sodium, $5.2 \mathrm{mEq}$. potassium, and $100 \mathrm{mEq}$. chloride per litre, and the blood urea was $52 \mathrm{mg}$. per $100 \mathrm{ml}$. The haemoglobin was $12 \mathrm{~g}$. per $100 \mathrm{ml}$. Five per cent dextrose was given intravenously by drip, and in half an hour she had recovered consciousness, having then been unconscious for at least 12 hours. For the first 24 hours she was treated with intravenous glucose, saline, and hydrocortisone and then with cortisone and fluorohydrocortisone by mouth. The day after admission the plasma contained $120 \mathrm{mEq}$. sodium, $5.4 \mathrm{mEq}$. potassium, $94 \mathrm{mEq}$. chloride, and $27 \mathrm{mEq}$. bicarbonate per litre. Over the next four weeks her mood fluctuated between elation and depression; she was at different times muddled, paranoid, and agitated, would sometimes sing loudly in the ward, but at times was apparently normal. The dose of cortisone was gradually reduced from $100 \mathrm{mg}$. to $25 \mathrm{mg}$. daily. By September 15 her emotional state was nearer normal and she was discharged home. She was given cortisone 25 mg. and fluorohydrocortisone $0.1 \mathrm{mg}$. daily. While in hospital she developed a dental abscess and some teeth were extracted. It was thought that dental sepsis might have been a factor precipitating the coma.

For the first week at home her behaviour was very abnormal. She was aggressive, impulsive, demanding, and sometimes offensive; she would interrupt conversations and push to the front of queues. She then behaved in a more normal manner for a few days, and apologized to neighbours whom she had insulted earlier. Following this her behaviour again became abnormal and ont September 30 she was readmitted to the London Hospital $\stackrel{?}{?}$ She was found to have tonsillitis, which was treated with penicillin. The blood pressure was $100 / 70 \mathrm{~mm}$. $\mathrm{Hg}$ and the plasma electrolytes again showed abnormalities characteristic of Addison's disease. The blood sugar waof $100 \mathrm{mg}$. per $100 \mathrm{ml}$. on two occasions. She was givent cortisone $25 \mathrm{mg}$. b.d. and fluorohydrocortisone $0.2 \mathrm{mg}$ b.d. by mouth. Because of continuing disturbed be? haviour she could not be managed in a general ward and she was transferred to the Maudsley Hospital on October 5.

Course in Maudsley Hospital.-On admission the physical findings were as before, with a resolving tonsillitis. The blood pressure was $100 / 60 \mathrm{~mm}$. $\mathrm{Hg}$ and she was afebrile. Mentally, she was restless, uncooperative, and strikingly distractible. She was grossly disorientated in time and place. Talk was plentiful and spontaneous; she alternately whispered and shouted, and was often incoherent. The mood was generally flat, with brief spells of tearfulness. She had fleeting delusional ideas largely based on mistaken perceptions, and she frequently misidentified other patients as her relatives. Memory was poor for both recent and remote events, and she was unable to perform simple calculations. The picture was thus typical of an organic confusional state.

For the first four days her condition remained unchanged. Food and drugs were taken with difficulty. The treatment she had been receiving was continued, and when she would not take her drugs by mouth they were given parenterally. The plasma electrolytes were normal. The blood sugar, estimated at random during the day on October 6 , was $74 \mathrm{mg}$. and on October 8 , $70 \mathrm{mg}$. per $100 \mathrm{ml}$. The fasting blood sugar on October 7 
was $52 \mathrm{mg}$. per $100 \mathrm{ml}$. An electroencephalogram (E.E.G.) on October 7 showed alpha rhythm at 11 to $12 \mathrm{c} / \mathrm{s}$ with a generalized abnormality consisting of an excess of slow and intermediate-slow activity.

From October 8 she was given glucose drinks every two hours. The next day she was less restless, took her food well, and was more rational. On October 10 she was much improved and at times rational. From then on improvement was uninterrupted. Cortisone was continued in the same total dose but from October 10 it was given in three eight-hourly doses. Fluorohydrocortisone was reduced to $0.1 \mathrm{mg}$. daily. Once she was eating her normal diet, glucose drinks were not given, but a milk drink or some food was given last thing at night and first thing in the morning. By October 17 no intellectual deficiencies could be found and the full-scale Wechsler I.Q. was 116. She was still somewhat emotionally labile, but her mood soon returned to normal and she remained perfectly well. Subsequently, the blood sugar was estimated at varying times on different days, and the lowest value obtained was $97 \mathrm{mg}$. per $100 \mathrm{ml}$. On four occasions the blood sugar was estimated after the patient had fasted until 9 a.m., which was much later than she would normally have eaten; the values at these times were 94 , 62,70 , and $88 \mathrm{mg}$. per $100 \mathrm{ml}$. A glucose tolerance test after recovery was normal.

Two later E.E.G.s showed a gradual improvement, but the abnormality had not completely disappeared on November 14, when she was quite well. In these E.E.G.s photic stimulation elicited a slow wave-and-spike discharge similar to that seen in the E.E.G. of the patient's daughter who is under investigation for a behaviour disorder.

In the nine months that have elapsed since her recovery she has been perfectly well.

\section{Discussion}

The presentation of Addison's disease in hypoglycaemic coma is rare. Gittleson (1956) reviewed the literature and reported a case. Neuropsychiatric disturbances have long been recognized as a feature of Addison's disease and they were referred to by Addison in his original description (Addison, 1855). Klippel (1899) described a patient with Addison's disease who developed frequent attacks of incoherence and shouting, sometimes followed by fits, regularly at 4 a.m. He recognized the importance of mental symptoms in Addison's disease, and referred to the 'encéphalopathie addisonienne'. It seems likely that the cause of his patient's attacks was hypoglycaemia. Woodbury (1958) in a comprehensive review stated that 'it has become increasingly evident that psychological derangements are an integral part of the disease syndrome'.

Our patient's chronic fluctuating organic psychosis was probably the result of a number of factors. First, recovery from hypoglycaemic coma lasting at least 12 hours might be expected to be slow. Secondly, it seems likely that during the patient's first admission and during the period at home her blood sugar level might at times have been abnormally low, although at the times that it happened to be measured it was normal. This is suggested by our finding of low blood sugar values at the time of her admission to the Maudsley Hospital, and by our later observation that the fasting blood sugar could drop as low as $62 \mathrm{mg}$. per $100 \mathrm{ml}$. This fluctuating hypoglycaemia might not only have delayed recovery from the initial damage, but also produced symptoms in its own right. Thorn, Koepf, Lewis, and Olsen (1940) have pointed out that symptoms of hypoglycaemia may develop at higher levels of blood sugar in patients with Addison's disease than in normals, and it is known that the E.E.G. of patients with Addison's disease shows a lowered threshold of cerebral reaction to hypoglycaemia (Engel and Margolin, 1942). The mental state in hypoglycaemia may not correlate closely with the blood sugar level at the time, and Fabrykant (1955) has suggested that clinical hypoglycaemic manifestations do not reflect a lowering of the blood sugar per se but rather derangements in brain metabolism and function which result from it. Thirdly, the dental sepsis and sore throat are likely to have contributed to the metabolic disturbance. Finally, the abnormality demonstrated in the E.E.G., of the same type as seen in the patient's daughter, although probably incidental, may possibly have increased the sensitivity of this patient's brain to metabolic derangements.

Our patient did not show any of the usual symptoms of hypoglycaemia, such as hunger or sweating, and in fact the only symptoms of it were mental. In patients with Addison's disease and psychiatric symptoms, it would thus seem important to consider whether chronic hypoglycaemia might not be the cause of the mental disturbance. This could be the case even though the blood sugar level is normal at the time of the disturbance, and it may also be possible that levels of blood sugar which are ordinarily considered normal are inadequate for the nutrition of the brain of the patient with Addison's disease. A therapeutic régime on the lines we adopted might be worth trying in such cases.

The prolonged confusional state in our case closely resembles that described by Blau and Hinton (1960) after coma in hypopituitarism. In their case hypotension was an important factor, though marked hypoglycaemia was present, and complete recovery of the psychosis occurred, as here. The excellent outcome in both cases after a prolonged organic psychosis is noteworthy.

\section{Summary}

A woman of 38 with Addison's disease developed hypoglycaemic coma, from which she recovered 
after treatment with glucose and corticosteroids. The coma was followed by an organic psychosis which lasted for two months. The main cause of this was thought to be fluctuating hypoglycaemia. The diagnostic and therapeutic implications are discussed. She recovered completely after intensive treatment with glucose by mouth.

This patient was under the care of Dr. Donald Hunter at the London Hospital and Dr. Felix Post at the
Maudsley Hospital. We wish to thank them for permission to publish.

\section{REFERENCES}

Addison, T. (1855). On the Constitutional and Local Effects of Disease of the Supra-Renal Capsules. S. Highley, London.

Blau, J. N., and Hinton, J. M. (1960). Lancet, 1, 408. Fabrykant, M. (1955). Metabolism, 4, is3.

Gittleson, N. (1956). Brit. med. J., 1,608.

Klippel, M. (1899). Rev. neurol., 7, 898.

Thorn, G. W., Koepf, G. F.,

Woodbury, D. M. (1958). Pharm. Rev. 10, 275 